\title{
The Valsalva manoeuvre and Antonio Valsalva (1666-1723)
}

\author{
E H Jellinek
}

J R Soc Med 2006;99:448-451

\section{INTRODUCTION}

The Valsalva manoeuvre remains a popular medical topic, with more than 100 publications per annum, 300 years after its first mention by Antonio Valsalva in Bologna in 1704 in his classical 'De aure humana tractatus'. ${ }^{1}$ In current usage it usually means: an acute rise in intrathoracic and intra abdominal pressure, brought about by contraction of the trunk muscles, right down to the pelvic floor, against a 'stop', at the glottis, but also more peripherally by the tongue in the nasopharynx, or at the lips and nostrils, or even outside the body, as in the blowing up of a column of mercury in a manometer. It is done automatically, and very briefly, in coughing and sneezing; and for longer periods in bodily functions like defaecation and parturition; or, more deliberately, in heavy lifting; in various sports; and in the blowing of wind instruments.

\section{THE EFFECTS OF THE MANOEUVRE}

The first study of its physiological effects was in 1850 when Ernst Heinrich Weber ${ }^{2}$ demonstrated the provocation of bradycardia, and possibly cardiac arrest, in himself, at a scientific meeting in Leipzig. More correctly, the observer was his medical brother, Eduard Friedrich Weber, as he lost consciousness and had a convulsion. A century later E P Sharpey-Schafer and his school ${ }^{3}$ described the great complexity of effects of the manoeuvre in the normal and in the failing circulation. More sophisticated investigations have continued, varying the force and the duration of the manoeuvre, and with more precise intrathoracic pressure recordings. ${ }^{4,5}$ Recent studies of the effects have ranged as far as changes in functional magnetic resonance imaging of the brain during the manoeuvre. ${ }^{6,7}$

The daily performance of the manoeuvre by everybody means that there will be coincidences of pathological events (especially in the constipated elderly), but the very real circulatory changes wrought by the manoeuvre also make causal connections very plausible, right up to sudden death. Non-fatal repetitive instances may be obviously attributable, e.g. cerebral symptoms, or visual disturbances from retinal bleeds, which are now indexed as 'Valsalva retinopathy'. ${ }^{8-10}$

7 Oxgangs Road, Edinburgh EH10 7BG, Scotland, UK
The manoeuvre also features in the headache literature (cough headaches, cluster headaches). ${ }^{11}$

More in keeping with Valsalva's original concern is the listing of the manoeuvre in otology as in altering middle ear pressure when the tympanic membrane is intact, or in the extrusion of secretions through a ruptured drum; this last rather old-fashioned use has its only definition in one reference text. ${ }^{12}$ Rarely, the manoeuvre may cause surgical emphysema, and, exceptionally, intracranial aerocoeles. ${ }^{13-15}$ Lastly, the manoeuvre comes into studies of bladder and bowel incontinence. ${ }^{16}$

\section{VALSALVA'S BIOGRAPHY AND CONTRIBUTIONS TO MEDICINE}

Antonio Valsalva was born in 1666 in Imola, then in the Papal States, and qualified in medicine at the nearby ancient university of Bologna. He became the favourite pupil, and later successor, of Marcello Malpighi (1628-1694), one of the originators of microscopy in medicine, and discoverer of capillaries in the lungs, the missing link in Harvey's circulation. In 1697 Valsalva became professor of anatomy, and later of surgery, in Bologna, and was also surgeon to the hospital for incurables. ${ }^{17,18}$

He checked routinely on his own clinical practice by post mortems; a custom he bequeathed to his own most eminent pupil, Giovanni Battista Morgagni (1682-1771), who soon moved from Bologna in the Papal States to the University of Padua in the Venetian Republic. Morgagni's eventual (1761) De sedibus et causis morborum ${ }^{19}$ was to be the world-wide guide to scientific medicine for over a century.

Valsalva's clinical practice in Bologna is said to have loosened the restrictions of the mentally ill in the incurables' hospital and elsewhere. ${ }^{17,18} \mathrm{He}$ found time for animal experiments - such as splenectomies, and the ligating of carotid and other arteries in dogs, and the reputedly lethal stimulation of the cerebellum in birds, which he proved compatible with some survival. Unlike Thomas Willis in Oxford, whom he quoted, he found that rupturing the eardrums of dogs allowed recovery of hearing.

Hearing was one of his chief interests, and his only published treatise was De aure humana tractatus ${ }^{1}$ in 1704. In this he extended the anatomy of Bartolomeo Eustachi (c.1500-1574) and his 'auditory tube', by descriptions of the muscles of the nasopharynx, the exact structure of the Eustachian tube, the ossicles, the cochlea and semicircular 


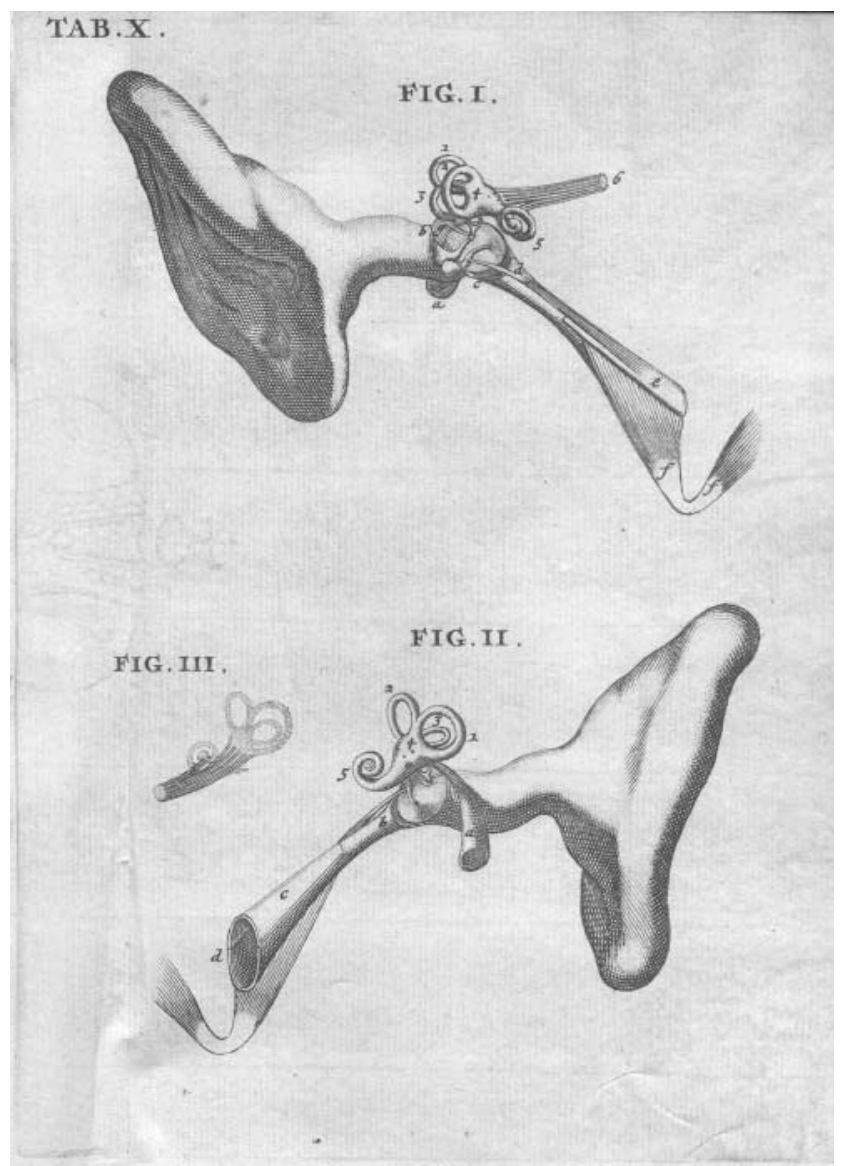

Figure 1 Valsalva's Tabula $X$, illustrating the normal anatomy of inner ear, eustachian tube and muscles

canals, and the foramina of the middle and inner ear (Figure 1). His relatively short Latin text of about 34000 words extends from descriptive normal anatomy in the first half of the book, and its uses in the second half, to conjectures from the gross pathologies of his era, infections and trauma, in particular.

The concurrence of pathology in the ear and brain, like bleeding from the ear after cranial trauma, and intracranial abscesses, etc., with ear infections, led Valsalva to postulate 'new' foramina linking the intracranial cavity with the ear. Unlike his other 'new' foramina for occipital veins (which he could illustrate), these could not figure in his illustrations; but he argued for such channels of drainage for pathological intracranial material into the ear and via Eustachi's tube into the nasopharynx, and, conversely, for the option of salubrious air to rise to the meninges from what has since been called his manoeuvre: ${ }^{1}$ [p. 84]

'. . I will explain about the expurgation of praeternatural cranial matters: he who has inflated his mouth and nose allows air to reach as far as the dura mater. It is clear that these foramina permit relief by extruding sanies [bloody matter] in penetrating head injuries from the cranial cavity through the wound when air is forced inwards with occluded mouth and nostrils. In fact by the same effort air is forced through the Eustachian tube to the tympanum and backwards through the foramina against the brain . . . demonstrated not once but by frequent experiments ... A sore of the tympanum whence ichor [watery discharge from a wound] flows into the auditory meatus . . . if with occluded mouth and nostrils air is compressed inwardly, this action will extrude sanies from the middle ear [and is] a remedial exercise, to be repeated, [and will lead to] extrusion of praeter-natural cerebral matter either via the wound, via the nostrils, via the mouth, or via the auditory meatus . . . with great benefit . . .'

This repetitive description of the manoeuvre is followed immediately in the text by Valsalva's observation on the contralaterality of cerebral lesions in strokes: 'In apoplexy when the right side of the body is affected the cause is found in the left cerebral hemisphere; when the left side is affected the cause is in the right'. It seemed worth stating this in 1704, and the book carried an imprimatur from the Holy Office in Bologna. It was later reiterated by Morgagni19 who allowed earlier similar views on this contralaterality, going back to antiquity (Aretaeus of Cappadocia, etc.), but it was to be floated in 1914 as 'the law of ValsalvaMorgagni'. ${ }^{20}$

\section{VALSALVA'S AND MORGAGNI'S PUBLICATIONS}

De aure humana tractatus, ${ }^{1}$ was republished in Utrecht (Trajecti ad Rhenum) in 1707 with 10 pull-out illustrationswith $1-4$ beautiful anatomical drawings (by Cavazzoni), engraved by 'H Lenting, Groningianus', of the muscles of the nasopharynx, of the tube, and of the middle and inner ear, and of the skull base. A third edition was published in Geneva in 1716.

Valsalva made no mention in his book of the role of the ear in balancing, nor of vertigo. But he included a clinical account of a vascular tumour at the top of the neck, to support the significance of his 'new' occipital veins and their foramina; this case had been reported to him by letter from Padua by his ex-pupil Morgagni, who was 22 in 1704.

Morgagni repaid his debt to his teacher by boosting Valsalva many years after his death in 1723. In 1741 he republished De aure humana tractatus for a fourth time in a Venice two-volume edition of Valsalva's Works (Opera Valsalvae . . et dissertationes anatomicae ${ }^{21}$ ) which contained in addition Valsalva's few unpublished treatises. One illustrated the aortic sinuses which also carry his name, i.e. small bulges above the aortic valves noted in dictionaries of eponyms. In his short biographical section Morgagni extols Valsalva as an honest and self-critical physician, and continues with over 200 pages of his dissertationes anatomicae (i.e. his own observations and opinions) stressing their 


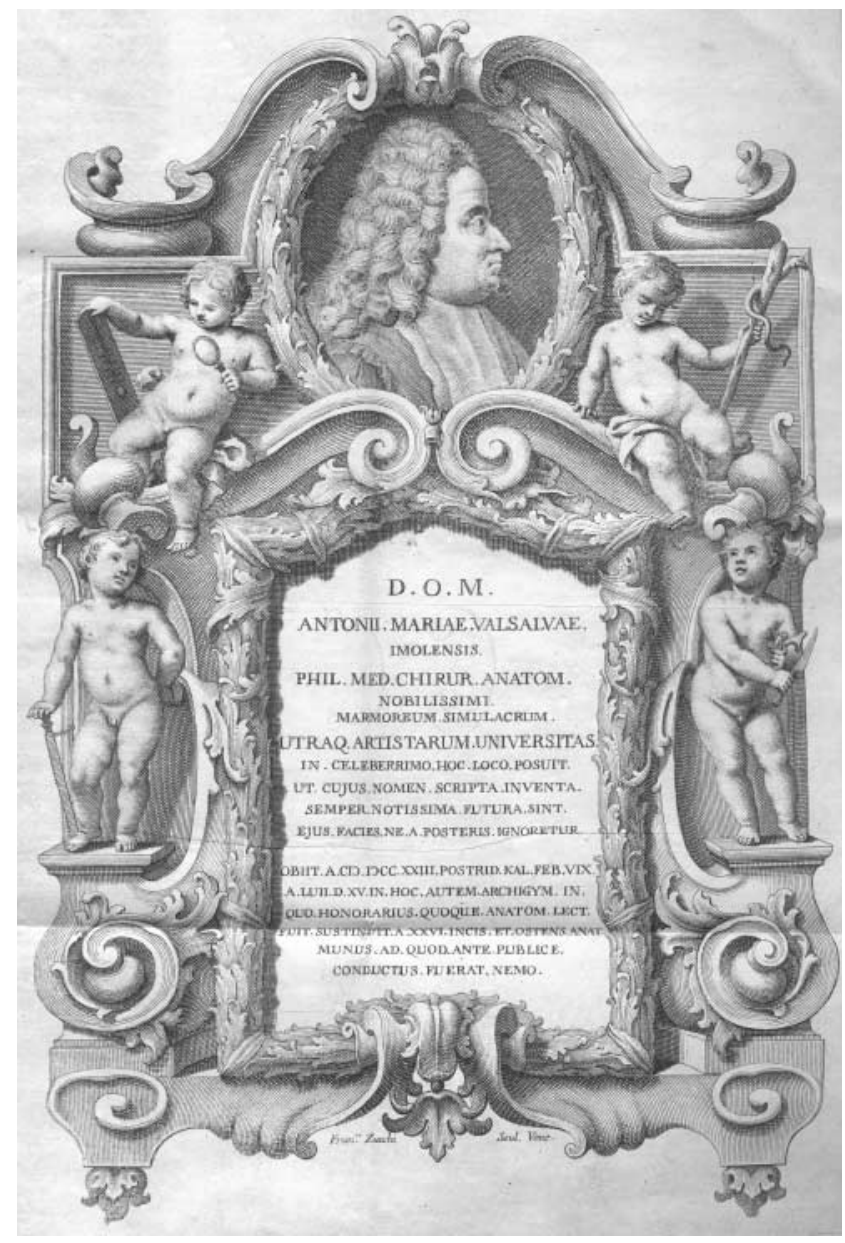

Figure 2 Frontispiece of Morgagni's 1741 Valsalvae opera showing profile of Valsalva on his marble memorial in Bologna university library

derivation from Valsalva; but he seemed unenthusiastic about Valsalva's 'new' foramina in his epistola VI, sections 5-8.

\section{MEMORIALS IN MARBLE AND PRINT}

Like his teacher Malpighi before him, Valsalva had been elected a foreign member of the Royal Society of London. His own university memorialized him in marble (Figure 2), which served 18 years after Valsalva's death as frontispiece to Morgagni's Opera Valsalvae et . . . Dissertationes Anatomicae. ${ }^{21}$ This work, and not the more renowned De sedibus et causis morborum ${ }^{19}$, as mis-stated by Dawson ${ }^{7}$, contains Morgagni's quotation of Valsalva dum clausis naribus et ore aer vi intro comprimitur [when air is forced inwards with occluded nostrils and mouth] in epistola VI, section 8. This was to become the Valsalva manoeuvre in the German literature, and then world-wide, about 20 years after Weber's hazardous self-experimentation in $1850 . .^{7}$ Morgagni's magnum opus De sedibus ${ }^{19}$, published in 1761 when he was 79, again had scores of references to Valsalva on many pathological topics but nothing about the 'manoeuvre' (Figure 3).

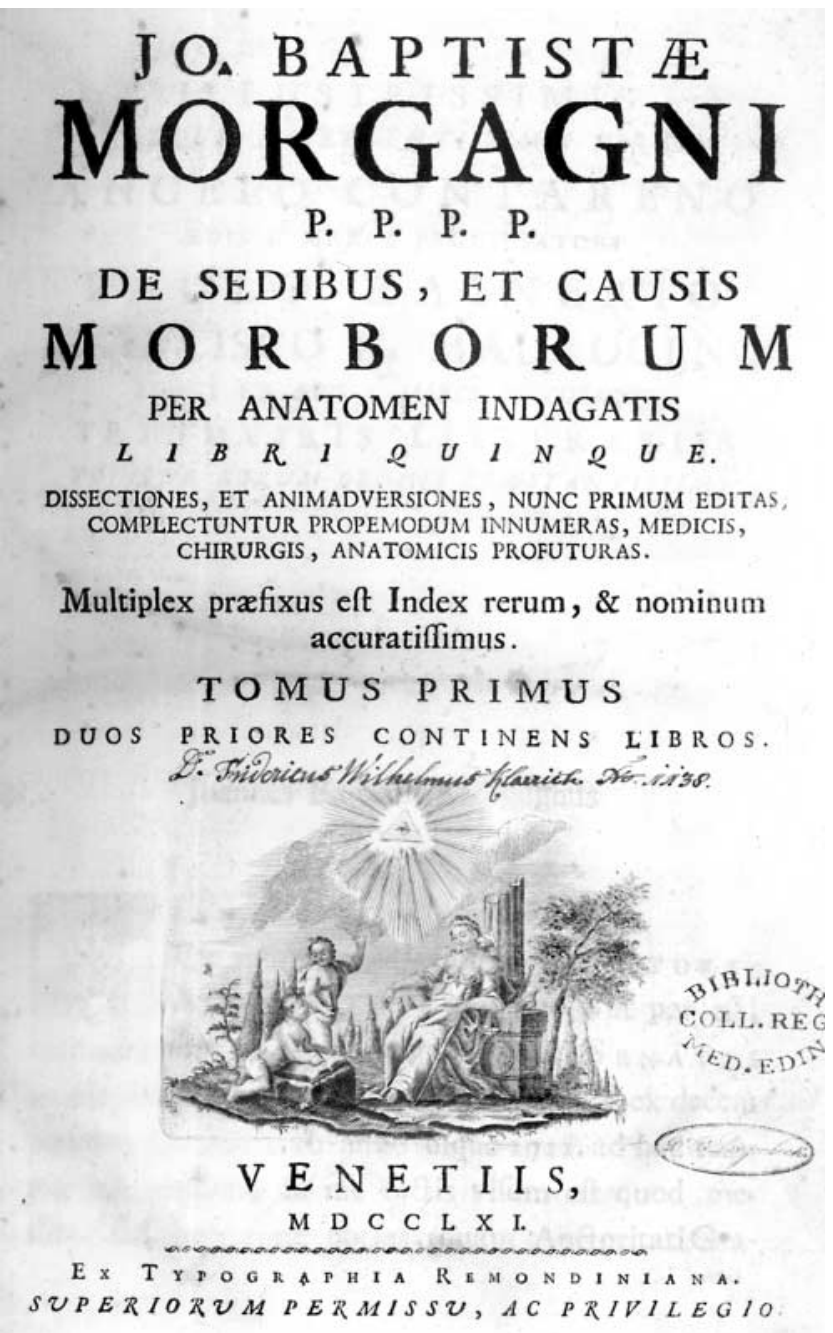

Figure 3 Title page of Morgagni's De sedibus et causis morborum $\ldots 1761$

\section{FALSE EPONYMITY AND TRUE FAME}

I have not found any statement of Valsalva's own recordnor of its context - in the many writings of the last 150 years on the physiological effects of the manoeuvre, on its wider practical use in assessing physical fitness, ${ }^{22}$ and in testing cardiac and autonomic function in the normal and in the failing heart. ${ }^{3-5}$

By his own account, Valsalva had used the manoeuvre in an attempt to prove the existence of non-existent foramina between the ear and the cranial cavity; and also to clear paraeternatural intracranial and middle-ear fluids via the then more prevalent drum perforations. Its unintended effects have been great advances in the understanding of the circulation.

Whatever the validity of his eponymous immortality, he remains one of the 'greats' of Italian science.

Acknowledgments I am obliged to Iain Milne and the library staff of the Royal College of Physicians, Edinburgh, 
for much help and guidance; to John Forrester for checking translation from the Latin text.

Competing interests None declared.

\section{REFERENCES}

1 Valsalva AM. De aure humana tractatus ... Utrecht: van de Water, 1707

2 Weber EF. Sur des essais d'arrêt volontaire de la circulation . . . et du coeur. Arch Gén de Méd 1853;i:399-411

3 Sharpey-Schafer EP. Effects of respiratory acts on the circulation. In: Handbook of Physiology, Vol. 2, Sec 3: Circulation. Washington, DC: American Physiological Society, 1965

4 Looga R. The Valsalva manoeuvre: critical review. Resp Physiol Neurobiol 2005; 147:39-49

5 Nishimura R, Tajik AJ. The Valsalva manoeuvre three centuries later. Mayo Clin Procs 2004;79:577-8

6 Henderson LA, Macey PM, Macey KE, et al. Brain responses with V manoeuvre revealed by functional MRI. J Neurophysiol 2002; 88:3477-86

7 Dawson PM. An historical sketch of the Valsalva manoeuvre. Bull Hist Med 1943;14:295-320

8 Kwok AK, Lai TY, Chan NR. Epiretinal membrane in Valsalva retinopathy. Am J Ophthalmol 2003;136:763-6

9 Markoff JI. High resistance wind instruments \& intraocular pressure. Ophthalmology 2001;108:635-6
10 Sbeity ZH, Mansour AM. Recurrent ret vein occlusion . . . wind instrument. Graefe's Arch Clin Exp Ophthalmol 2004;242:428-31

11 Ko J, Todd D, Rozen MD. Valsalva induced cluster headache. Headache 2002;42:301-2

12 Schmidt JF. Medical discoveries: who and when. Springfield: C Thomas, 1959

13 Ramsay D, Finlay D. Surgical emphysema ... repeated Valsalva . . laceration of buccal mucosa. Eur J Emerg Med 2000;7:73-4

14 Littrell LA, Leutmer P, Lane J, Driscoll L. Progressive . . . pneumatisation ... habitual Valsalva manoeuvre. Am J Neuroradiol 2004; $25: 491-3$

15 Schrijver HM, Berendse H. Pneumocephalus by $\mathrm{V}$ manoeuvre. Neurology 2003;60:345-6

16 Peschers UM, Jundt K, Dimpfl T. Cough and Valsalva leak-points in stress incontinent women. Neurourol Urodyn 2000;19:677-81

17 Busacchi V. A M Valsalva. Minerva Medica 1967;58:3513-17

18 Busacchi V. A M Valsalva. Münchn Med Wschr 1968;110:60-3

19 Morgagni GB. De sedibus et causis morborum . . 1761 (The seats and causes of diseases). Transl. Alexander B, London 1769). Birmingham: Classics of Medicine Library, 1983

20 Ebstein E. Das Valsalva-Morgagnische Gesetz. D Zschr Nervenheilk 1914:53:130-6

21 Morgagni GB. Valsalvae opera . . ., 2 vols. Venice: F Pitteri, 1741

22 Flack M,Burton HL. . . s significance of the $40 \mathrm{~mm}$ mercury test. $J$ Physiol 1922;56:1-li 